\title{
Health-related Quality of Life and Survival in Pulmonary Arterial Hypertension
}

\author{
Stephen C. Mathai ${ }^{1}$, Tomeka Suber ${ }^{2}$, Rubina M. Khair ${ }^{1}$, Todd M. Kolb ${ }^{1}$, Rachel L. Damico ${ }^{1}$, and Paul M. Hassoun ${ }^{1}$ \\ ${ }^{1}$ Division of Pulmonary and Critical Care Medicine, Johns Hopkins University School of Medicine, Baltimore, Maryland; and ${ }^{2}$ Division \\ of Pulmonary, Allergy, and Critical Care Medicine, University of Pittsburgh School of Medicine, Pittsburgh, Pennsylvania
}

\begin{abstract}
Rationale: Pulmonary arterial hypertension is a progressive disease with high morbidity and mortality despite advances in medical therapy. The relationship between patient-related outcomes, such as healthrelated quality of life (HRQOL), and survival is not well described.

Objective: To assess the relationship between HRQOL and outcomes in patients with pulmonary arterial hypertension.

Methods: Consecutive patients with right heart catheterization-proven pulmonary arterial hypertension who completed the Medical Outcomes Survey Short Form-36 survey (SF-36) were included. Demographic, clinical, physiological, and hemodynamic data were collected at baseline. Survival was assessed from the time of diagnosis of pulmonary arterial hypertension. Cox proportional hazard models were constructed to assess the relationship between HRQOL and transplant-free survival.
\end{abstract}

Measurements and Main Results: Eighty-seven patients with pulmonary arterial hypertension were enrolled and followed prospectively for a median of 3.8 years. At baseline, HRQOL was significantly worse than U.S. normal values for six of eight domains of the SF-36. Several domains demonstrated moderate correlation ( $r$ value $\geqslant 0.40$ ) with 6 -minute-walk distance and World Health Organization functional class; there were no significant associations with hemodynamics. In univariable Cox proportional hazard models, six of eight domains and both summary scores were significantly associated with survival. In multivariable models, adjusted for age, disease type, and cardiac function, these relationships largely persisted.

Conclusions: In this cohort of patients with pulmonary arterial hypertension, HRQOL, as assessed by the SF-36, was strongly associated with transplant-free survival. These relationships persisted when controlling for potential confounders such as disease type and disease severity. These findings suggest that HRQOL may be an important predictor of outcomes in pulmonary arterial hypertension and therefore a target for future therapeutic interventions.

Keywords: quality of life; pulmonary hypertension; outcomes

(Received in original form December 12, 2014; accepted in final form October 6, 2015)

Supported by National Heart, Lung, and Blood Institute grant K23 HL093387 and by a Pulmonary Hypertension Association K23 Supplemental Award (S.C.M.) Author Contributions: S.C.M.: conception/design, analysis and interpretation of data, drafting and revising manuscript, final approval of manuscript; T.S.: conception/design, analysis and interpretation of data, revision and final approval of manuscript; R.M.K.: conception/design, analysis and interpretation of data, revision and final approval of manuscript; T.M.K.: conception/design, analysis and interpretation of data, revision and final approval of manuscript; R.L.D.: analysis and interpretation of data, revision and final approval of manuscript; P.M.H.: conception/design, analysis and interpretation of data, revision and final approval of manuscript.

Correspondence and requests for reprints should be addressed to Stephen C. Mathai, M.D., M.H.S., Johns Hopkins University School of Medicine, Division of Pulmonary and Critical Care Medicine, 1830 East Monument Street, Room 540, Baltimore, MD 21205. E-mail: smathai4@jhmi.edu

This article has an online supplement, which is accessible from this issue's table of contents at www.atsjournals.org

Ann Am Thorac Soc Vol 13, No 1, pp 31-39, Jan 2016

Copyright (C) 2016 by the American Thoracic Society

DOI: 10.1513/AnnalsATS.201412-5720C

Internet address: www.atsjournals.org

Pulmonary arterial hypertension $(\mathrm{PAH})$ is a chronic disease of the pulmonary vasculature leading to significant morbidity and mortality (1). Recent advances in therapeutics have improved symptoms, functional capacity, and survival in $\mathrm{PAH}$ to varying degrees; however, $\mathrm{PAH}$ remains a disease without a cure with a median survival of 5 to 7 years (2). Prediction of survival in $\mathrm{PAH}$ is thus an important consideration for the management of patients with this disease and informs individual therapeutic decisions.

Traditionally, objective parameters of disease severity have been used to predict outcomes in PAH. Invasive measures of hemodynamics were used to construct the initial prediction equation for survival in PAH using data from the National Institutes of Health Registry of Primary Pulmonary Hypertension (3). More recent prediction equations have used a 
combination of invasive measures and noninvasive measures, such as 6-minute-walk distance (6MWD) and World Health Organization (WHO) functional class, along with serologic markers of renal function and right ventricular strain (4-6). Similarly, other characteristics, such as age, sex, disease type (idiopathic PAH [IPAH] vs. connective tissue disease-associated $\mathrm{PAH}$ [CTD-PAH]), and right ventricular function assessed by cardiac magnetic resonance imaging or echocardiography, among others, have been shown to predict outcome in $\mathrm{PAH}$ (7-13). However, there are few data examining the potential role of patient-reported outcomes (PRO) in the prognosis of PAH.

A PRO is any measurement of a patient's health that is directly assessed by the patient (14). Frequently, PROs assess health-related quality of life (HRQOL), the "functional effect of an illness and its consequent therapy upon a patient, as perceived by the patient," (15) using questionnaires such as the Medical Outcomes Survey Short-Form 36 (SF-36) (16). Extensive literature exists regarding the relationship between HRQOL and disease, including its prognostic importance, in chronic cardiopulmonary diseases, such as COPD (17-19) and left heart failure (LHF) (20-22). However, most studies in $\mathrm{PAH}$ have focused on short-term changes in HRQOL in response to novel therapies, typically as secondary outcomes measures in clinical trials.

As documented in a recent systematic review (23), although HRQOL demonstrates statistically significant improvement in response to $\mathrm{PAH}$-specific therapies in general, (1) the response can be variable, (2) the clinical relevance of this change is unclear, and (3) there are limited data regarding the prognostic significance of HRQOL in PAH. One recent observational study in a mixed population of patients with IPAH and chronic thromboembolic pulmonary hypertension (CTEPH) demonstrated a significant relationship between baseline HRQOL using a disease-specific measure (Cambridge Pulmonary Hypertension Outcome Review [CAMPHOR]) and clinical deterioration, defined as need for additional PAH therapy, hospitalization, or death (24). Similarly, using the Minnesota Living with Heart Failure Questionnaire, a heart failurespecific tool, Cenedese and colleagues found a significant association between baseline HRQOL and survival in mixed cohort of patients with IPAH and CTEPH (25).
There are few data examining the relationship between generic measures of HRQOL and outcomes in PAH. One recent study by Fernandes and colleagues in 54 patients with various forms of $\mathrm{PAH}$ in which HRQOL was assessed at baseline and after 16 weeks of therapy demonstrated the predictive value of baseline and follow-up values in the physical component summary score of the SF-36 at 36 months (26). However, the authors did not conduct multivariable analyses to assess the relationship between HRQOL and outcomes in this cohort.

Because generic measures of HRQOL, such as the SF-36, are commonly used in clinical trials of $\mathrm{PAH}$ therapies, and prior studies suggest that the SF-36 may demonstrate superior discrimination and fewer floor or ceiling effects as seen with the Minnesota Living with Heart Failure Questionnaire in PAH (27), we sought to evaluate the association between HRQOL and transplant-free survival in a large cohort of patients with PAH. We hypothesized that poorer HRQOL would be associated with poorer outcomes in $\mathrm{PAH}$ and that these associations would persist when adjusting for disease severity.

This material was presented previously in abstract form (28).

\section{Methods}

Data were collected prospectively from the Johns Hopkins Pulmonary Hypertension Program, which maintains a registry of all patients evaluated. The Institutional Review Board of Johns Hopkins University approved the registry and this specific analysis; written consent was obtained from all patients. Consecutive outpatients evaluated for possible pulmonary hypertension $(\mathrm{PH})$ were enrolled in the registry and asked to complete an SF-36 survey at initial evaluation. Patients who subsequently were diagnosed with either IPAH or CTD-PAH were included in the current study.

The SF-36 is a generic instrument used to assess HRQOL. The SF-36 consists of eight domains: physical functioning, role limitations-physical, bodily pain, general health, vitality, social functioning, role limitations-emotional, and mental health (29). These domains can be compiled into summary scores for the physical and mental components; the physical component summary score (PCS) and mental component summary score (MCS). The SF-36 scores range from 0 to 100 , with higher scores indicating better HRQOL. Summary scores are scaled to a mean of 50 and standard deviation of 10 in the general U.S. population. The SF-36 has been validated and demonstrated responsiveness to change in a variety of patient groups; it is commonly used in PAH clinical trials $(30,31)$.

$\mathrm{PAH}$ was defined by right heart catheterization as per recent consensus guidelines (32) as a mean pulmonary artery pressure greater than or equal to $25 \mathrm{~mm}$ $\mathrm{Hg}$, pulmonary capillary wedge pressure less than or equal to $15 \mathrm{~mm} \mathrm{Hg}$, and a pulmonary vascular resistance greater than 3 Wood units, in the absence of other known causes of PH. Pulmonary function testing, 6-minute-walk test (6MWT), computed tomography of the chest, and echocardiography closest to the initial right heart catheterization were reviewed and recorded. Patients with either significant obstructive lung disease, defined as $\mathrm{FEV}_{1}$ less than $60 \%$ predicted accompanied by radiographic evidence of emphysema or interstitial lung disease, defined as a total lung capacity less than $70 \%$ predicted, were excluded from the study cohort (33). Similarly, patients with evidence of chronic thromboembolic disease and $\mathrm{PH}$ based on ventilation-perfusion scans, computed chest tomography angiograms, and/or pulmonary angiography were excluded. Connective tissue disease was defined according to consensus guidelines (34-37).

Survival was defined as time from completion of the SF-36 to death, and patients were censored at the time of lung transplantation. If a subject completed the SF-36 after the diagnostic heart catheterization, survival time was left truncated from the time of survey completion to minimize immortal time bias. Vital status was ascertained by review of the medical record, phone contact, and the Social Security Death Index.

\section{Statistical Analysis}

Continuous variables were summarized by mean $\pm \mathrm{SD}$ or median (range) and compared using an unpaired $t$ test or the Wilcoxon rank-sum test where appropriate. Categorical variables were compared using the Chi-square statistic. A two-tailed $P$ value with a significance level of 0.05 was used to detect statistically significant 
differences between groups. Subjects were stratified by median PCS score based on prior data showing the predictive value of this parameter in PAH (26).

Factors associated with transplant-free survival were ascertained by univariable Cox proportional hazard models in patients whose SF-36 was collected within 180 days of the diagnostic right heart catheterization (38). Variables found to be significant in univariable analysis $(P<0.15)$, shown previously to predict survival in $\mathrm{PAH}$, and potential confounders of the relationship between HRQOL parameters and outcome were incorporated into multivariable models. Variables that were found to be collinear by variance inflation factor testing in multiple linear regression were excluded from Cox multivariable analyses (e.g., 6MWD). Similarly, although not reaching the threshold for collinearity by variance inflation factor testing, WHO functional class imparted significant changes $(>10 \%)$ in crude compared with adjusted point estimates of hazard for several domains of the SF-36 when included in multivariable models and was thus removed from subsequent models.
The proportional hazards assumption was examined for all covariates using a continuous time-varying predictor and generalized linear regression of scaled Schoenfeld residuals on function of time $(39,40)$. Time-to-event analyses were performed using the Kaplan-Meier product limit estimator. Subjects who underwent organ transplantation were censored at the time of transplantation $(n=2)$. All analyses were performed using STATA version 12.0 (StataCorp, College Station, TX).

\section{Results}

\section{Patient Characteristics}

Between January 2004 and January 2013, of the approximately 1,800 new patients evaluated at the Johns Hopkins Pulmonary Hypertension Program, 196 were diagnosed with either IPAH or CTD-PAH as defined above. Of these patients, 112 completed the SF-36 survey. Twenty-five patients were excluded because they had missing clinical data $(n=22)$ or informed consent for this study was not obtained $(n=3)$. Thus, 87 subjects were included in the current study.
The demographic and clinical characteristics of the 87 subjects included in this cohort are summarized in Table 1 . Overall, the majority of subjects were white women around 56 years of age. Most had completed at least some college and about half were married at the time of enrollment. The majority were either receiving disability benefits or retired. More than half the cohort was WHO functional class III or IV at enrollment. Distance achieved during 6MWT showed moderate reduction in functional capacity at baseline. Hemodynamic measurements confirmed $\mathrm{PAH}$ and were consistent with moderately severe disease with an average mean pulmonary artery pressure of $47 \mathrm{~mm} \mathrm{Hg}$ and a pulmonary vascular resistance of 10 Wood units.

When stratified by median value of the PCS, some significant differences in characteristics were found. Patients with high PCS scores tended to be younger ( $53 \pm$ 14 vs. $59 \pm 14$ yr; $P=0.04$ ), but there were no significant differences in sex or race distribution between disease types. Similar proportions of subjects were married, had completed at least some college, and were

Table 1. Demographic, social, functional, and hemodynamic characteristics

\begin{tabular}{|c|c|c|c|c|}
\hline & Overall $(n=87)$ & High PCS $(n=47)$ & Low PCS $(n=40)$ & $P$ Value \\
\hline Age, mean (SD), yr & $56(14)$ & $53(14)$ & $59(14)$ & 0.04 \\
\hline Sex, female & 69 (79) & $37(78)$ & $32(80)$ & 0.88 \\
\hline Race, white & $68(78)$ & $35(74)$ & $33(83)$ & 0.50 \\
\hline Marital status, married & $50(57)$ & $26(55)$ & $24(60)$ & 0.77 \\
\hline Employment, disability/retired & $52(60)$ & $25(53)$ & $27(67)$ & 0.37 \\
\hline Education, college/graduate school & $53(57)$ & $25(53)$ & $25(63)$ & 0.52 \\
\hline \multicolumn{5}{|l|}{ WHO functional class } \\
\hline I & $9(11)$ & $6(14)$ & $3(8)$ & 0.01 \\
\hline II & 33(40) & $23(52)$ & $10(26)$ & \\
\hline III & $38(45)$ & $15(34)$ & $23(58)$ & \\
\hline IV & $3(4)$ & $0(0)$ & $3(8)$ & \\
\hline 6-min walk distance, mean (SD), m & $330(114)$ & $375(101)$ & $273(105)$ & $<0.001$ \\
\hline Right atrial pressure, mean (SD), mm Hg & $9(5)$ & $8(4)$ & $11(6)$ & 0.01 \\
\hline Mean pulmonary artery pressure, mean (SD), mm Hg & $47(14)$ & $48(16)$ & $46(13)$ & 0.63 \\
\hline Pulmonary capillary wedge pressure, mean (SD), mm Hg & $11(4)$ & $10(4)$ & $12(4)$ & 0.02 \\
\hline Cardiac output, mean (SD), L/min & $4.4(1.4)$ & $4.3(1.3)$ & $4.4(1.6)$ & 0.82 \\
\hline Cardiac index, mean (SD), L/min/m² & $2.3(0.7)$ & $2.4(0.7)$ & $2.2(0.8)$ & 0.27 \\
\hline Pulmonary vascular resistance, mean (SD), WU & $10(6)$ & $10(6)$ & $9(5)$ & 0.54 \\
\hline \multicolumn{5}{|l|}{ Initial PAH therapy } \\
\hline Phosphodiesterase inhibitor & $56(64)$ & $32(68)$ & $24(60)$ & 0.65 \\
\hline Endothelin receptor antagonist & $20(23)$ & $10(21)$ & $10(25)$ & 0.74 \\
\hline $\begin{array}{l}\text { Prostacyclin analog, inhaled, subcutaneous, } \\
\text { intravenous }\end{array}$ & $4(3)$ & $1(2)$ & $3(8)$ & 0.19 \\
\hline Combination therapy, oral only & $7(8)$ & $2(4)$ & 5 (12) & 0.10 \\
\hline Supplemental oxygen use & $23(26)$ & $10(21)$ & $13(32)$ & 0.09 \\
\hline Follow up time, median (range), yr & $3.8(1.1-8.9)$ & $3.7(0.6-10.5)$ & $3.1(0.6-7.0)$ & 0.07 \\
\hline
\end{tabular}

Definition of abbreviations: $\mathrm{PAH}=$ pulmonary arterial hypertension; $\mathrm{PCS}=$ Physical Component Summary score; WHO = World Health Organization; WU = Wood unit.

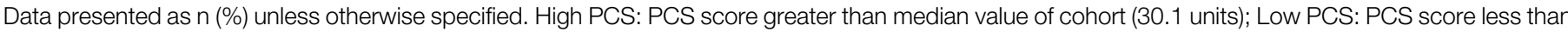
median of the cohort. 
either retired or receiving disability. Significant differences in functional capacity as assessed by WHO functional class or 6MWD were found between groups, with those in the high PCS group demonstrating better functional status in both parameters. Hemodynamics revealed significantly lower right atrial pressure in the high PCS group than in the low PCS group, but other parameters did not differ between groups.

\section{HRQOL Domains and Summary Scores}

The median time between diagnostic right heart catheterization and administration of the SF-36 was 18 days (range, -66 to $+180 \mathrm{~d})$. The majority of subjects $(75 \%)$ completed the survey within \pm 30 days of the diagnostic heart catheterization. As shown Figure 1, HRQOL differed significantly from U.S. normative values in six out of eight domains. In the physical domains (physical function, role physical, body pain, and general health), subjects with PAH had significantly depressed average scores. However, in the mental domains, only one of the four domains (vitality) was significantly depressed compared with U.S. norms. Interestingly, although social function and role emotional scores did not differ from U.S. norms, mental health scores were actually higher than the U.S. norms. When compared between the high and low PCS groups, scores in six of the eight domains were significantly lower in the low PCS group; there were no differences in mental health or social functioning domains between the groups (data not shown).

\section{Relationship between HRQOL and Demographic, Functional, and Hemodynamic Parameters}

As shown in Table 2, there were significant correlations between several domains and summary scores of the SF-36 and subjectspecific parameters. Although demographic characteristics, such as age, sex, and race, were not associated with individual domains or summary scores, functional assessments, such as WHO functional class and $6 \mathrm{MWD}$, were significantly associated with all domains and summary scores. The strongest association between functional assessments and HRQOL were seen with physical domains such as physical function

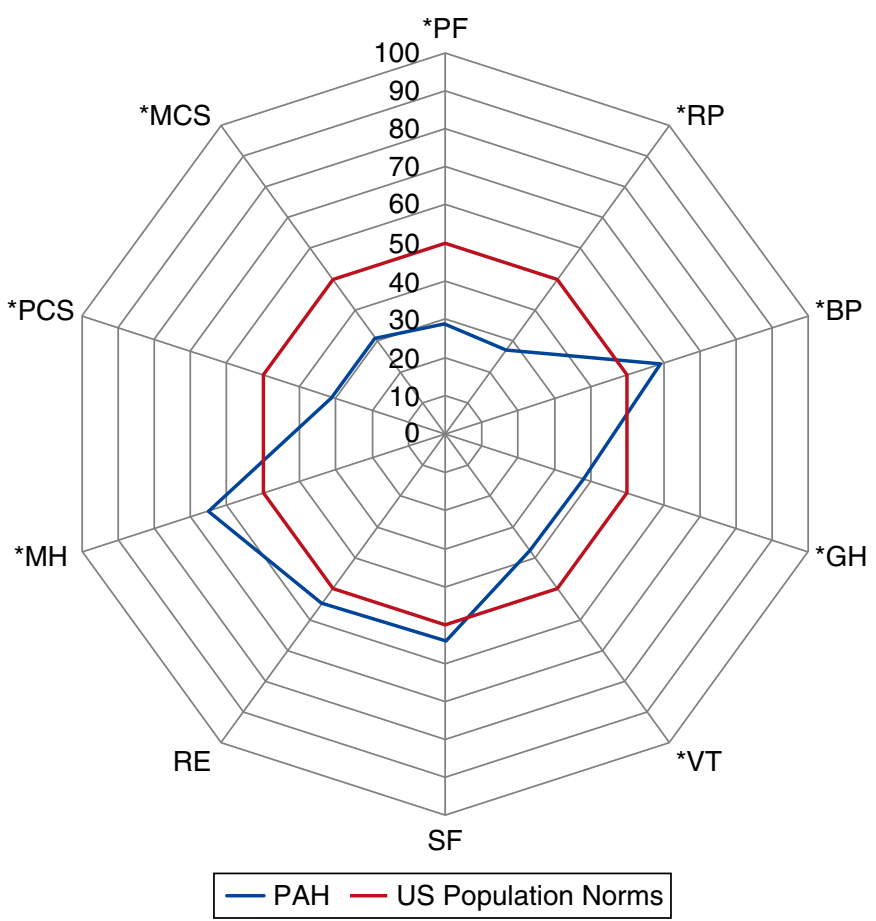

Figure 1. Spider plot of individual domain and summary scores in pulmonary arterial hypertension (PAH) versus U.S. population normative values. All values presented as means. ${ }^{*} P<0.05$ for comparison with U.S. population norms. $\mathrm{BP}=$ body pain; $\mathrm{GH}=$ general health; $\mathrm{MCS}=$ mental component summary; $\mathrm{MH}=$ mental health; $\mathrm{PCS}=$ physical component summary; $\mathrm{PF}=$ physical functioning; $\mathrm{RE}=$ role emotional; $\mathrm{RP}=$ role physical; $\mathrm{SF}=$ social functioning; $\mathrm{VT}$ = vitality.

$(r=-0.51, P<0.001$ and $r=0.60, P<$ 0.001 for WHO functional class and $6 \mathrm{MWD}$, respectively). However, mental health domains were also associated with functional assessments, most notably in social function $(r=0.56$, $P<0.001$ and $r=-0.40, P<0.001$ for WHO functional class and $6 \mathrm{MWD}$, respectively). Interestingly, hemodynamic parameters were either not associated or only marginally associated with HRQOL parameters.

\section{HRQOL Parameters and Outcomes}

After a median follow up of 4 years, 40 subjects died and 2 underwent lung transplantation. As shown in Figure 2, subjects with a PCS score below the median had a significantly worse survival than those with a PCS score above the median (log-rank $\chi^{2}=5.74, P=0.02$ ).

In univariable Cox proportional hazard models, six of eight domains were significantly associated with outcomes; only vitality and role emotional scores were not found to be associated with outcome (Table 3). Multivariable models were constructed to examine the relationship between HRQOL and outcomes adjusting for potential confounders. As shown in Table 4, when adjusted for age, disease type (IPAH vs. CTD-PAH), and cardiac function, six out of eight domains of the SF-36 were associated with outcomes.

Notably, all four physical function domains (physical function, role physical, body pain, and general health) were significantly associated with survival. Although the mental component summary predicted transplant-free survival, the physical component summary did not. Analyses adjusting for sex and race were conducted and yielded similar results (see Table E1 in the online supplement). However, multivariable analyses including WHO functional class instead of cardiac index as a covariate led to significant changes in the point estimate of hazard ratios (HRs) and strength of association for many of the domains, consistent with confounding. Sensitivity analyses were performed using data restricted to those subjects whose SF-36 was completed within \pm 30 days of diagnosis of PAH ( $\mathrm{n}=$ 65) to capture those most likely to be treatment naive; the observed associations between HRQOL domains and summary scores and outcomes were found to be similar (data not shown). 
Table 2. Correlation between Medical Outcomes Survey Short Form-36 survey domains and noninvasive and invasive parameters

\begin{tabular}{|c|c|c|c|c|c|c|}
\hline Domain & WHO Functional Class & 6MWD & RAP & mPAP & Cardiac Index & PVR \\
\hline Physical function & $-0.51^{\star}$ & $0.60^{*}$ & -0.18 & 0.004 & $0.21^{*}$ & -0.04 \\
\hline Role physical & $-0.38^{\star}$ & $0.48^{*}$ & -0.19 & -0.04 & 0.13 & -0.08 \\
\hline Body pain & $-0.24^{*}$ & $0.31^{*}$ & 0.05 & 0.17 & 0.12 & 0.10 \\
\hline General health & $-0.28^{\star}$ & $0.40^{\star}$ & -0.06 & 0.05 & 0.04 & 0.11 \\
\hline Vitality & $-0.28^{*}$ & $0.40^{*}$ & -0.08 & -0.03 & 0.09 & 0.05 \\
\hline Social function & $-0.40^{\star}$ & $0.56^{\star}$ & -0.27 & -0.20 & $0.35^{\star}$ & $-0.24^{\star}$ \\
\hline Role emotional & $-0.29^{\star}$ & $0.36^{\star}$ & -0.06 & -0.12 & 0.004 & -0.04 \\
\hline Mental health & $-0.37^{\star}$ & $0.44^{*}$ & $-0.23^{*}$ & -0.20 & 0.18 & -0.12 \\
\hline Physical component summary & $-0.42^{*}$ & $0.58^{\star}$ & -0.11 & 0.11 & 0.16 & 0.05 \\
\hline Mental component summary & $-0.37^{\star}$ & $0.45^{\star}$ & -0.14 & -0.14 & 0.12 & -0.06 \\
\hline
\end{tabular}

Definition of abbreviations: $6 \mathrm{MWD}=6$-minute-walk distance; $\mathrm{mPAP}=$ mean pulmonary artery pressure; $\mathrm{PVR}=$ pulmonary vascular resistance; $\mathrm{RAP}=$ right atrial pressure; $\mathrm{WHO}=$ World Health Organization.

Data presented as $r$ values.

${ }^{\star} P<0.05$

\section{Discussion}

In this study, we find that HRQOL as assessed by the SF-36 is strongly associated with outcomes in PAH. Furthermore, these relationships between HRQOL and survival persist even when controlling for demographic, etiologic, and hemodynamic parameters. Thus, our results suggest that patient-important parameters such as HRQOL are an important determinant of outcomes in PAH.

In our cohort of patients with $\mathrm{PAH}$, we found significant differences in HRQOL in patients with $\mathrm{PAH}$ when compared with U.S. norms, with numerically lower scores in the physical functioning domains, physical component summary score, and mental component summary score. However, unlike prior studies in PAH, only five of eight domains were depressed compared with U.S. norms and, in fact, two domains (body pain and mental health) were improved compared with U.S. norms $(41,42)$. The reasons for these differences are unclear, but may, in part, be related to differences in patient populations. The current study included nearly equal numbers of patients with IPAH and $\mathrm{PAH}-$ systemic scleroderma (PAH-SSc); the other studies included patients with various forms of PAH including non-SSc connective tissue diseases, portopulmonary hypertension, and those with other forms

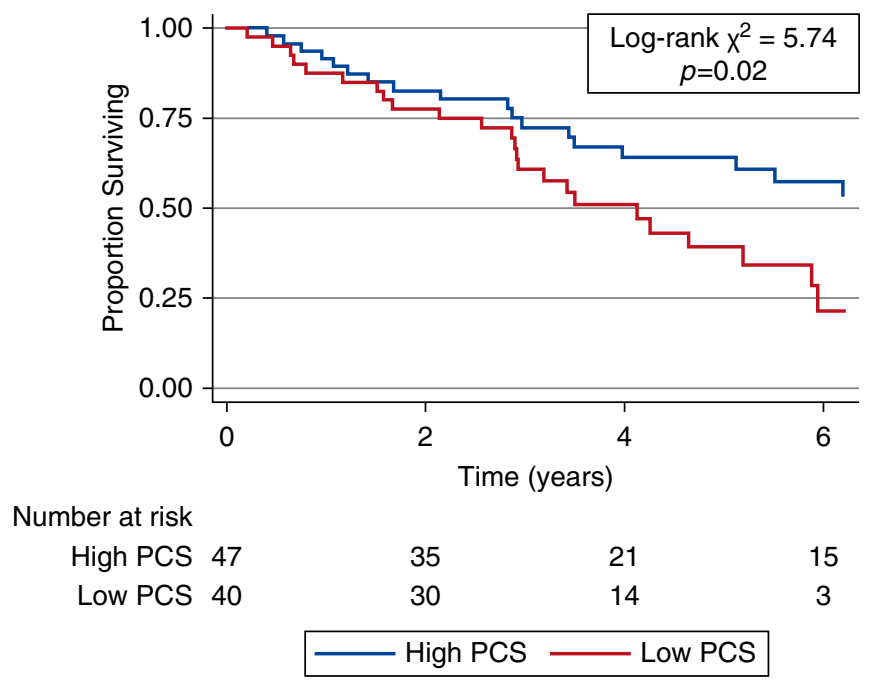

Figure 2. Survival stratified by Medical Outcomes Survey Short Form-36 survey (SF-36) physical component summary (PCS) score. High PCS = PCS greater than median score of cohort (median = 30.1 units); Low PCS = PCS less than median score of cohort.

of $\mathrm{PH}$ such as chronic thromboembolic PH. Similar to other studies, we found moderate to strong associations between individual domains and summary scores of the SF-36 and noninvasive parameters (WHO functional class and 6MWT), with the strongest associations found between 6MWT and the SF-36 parameters.

Furthermore, there were no significant relationships found between invasive hemodynamics and the SF-36, as has been demonstrated in prior studies, highlighting the complex relationship between patient perception and disease pathogenesis.

Survival analyses show a strong, consistent relationship between HRQOL parameters and outcomes in this cohort. In univariable analyses, six of eight domains and both summary scores were associated with survival. The HR point estimates range from 2 to $5 \%$ for each unit change in domain or summary score. Thus, even small changes in these parameters may have a significant relationship to outcomes in PAH.

The relationship between HRQOL parameters and survival remained strong when controlling for potential confounders such as age, disease type (IPAH vs. SSc$\mathrm{PAH}$ ), and disease severity as assessed by cardiac index. Six of the eight domains, including all of the physical function domains, were significantly associated with outcomes. Interestingly, the PCS did not demonstrate a statistically significant association with outcomes when controlling for age, disease type, and cardiac function, whereas the MCS did predict survival.

Despite a renewed focus on patientimportant outcomes in many chronic diseases including lung disease, most studies of PAH therapeutics have assessed 
Table 3. Univariable Cox proportional hazard models

Parameter
Physical function
Role physical
Body pain
General health
Vitality
Social function
Role emotional
Mental health
Physical component summary
Mental component summary

HR $(95 \% \mathrm{Cl})$
$0.98(0.97-0.99)$
$0.98(0.97-0.99)$
$0.98(0.97-0.99)$
$0.98(0.97-0.99)$
$0.98(0.97-1.00)$
$0.98(0.97-0.99)$
$0.99(0.98-1.00)$
$0.97(0.96-0.99)$
$0.95(0.92-0.98)$
$0.97(0.95-0.99)$

$P$ Value

Definition of abbreviations: $\mathrm{Cl}=$ confidence interval; $\mathrm{HR}=$ hazard ratio.

Data presented as estimates of hazard for transplant-free survival per 1-point increase in Medical Outcomes Survey Short Form-36 survey parameter.

functional capacity, as assessed by the $6 \mathrm{MWT}$, as the primary outcome measure (43). However, recent studies have highlighted the limitations of the 6MWT as a surrogate for survival in $\mathrm{PAH}$, demonstrating a lack of association between changes in 6MWT and outcomes $(44,45)$. WHO functional class has also been widely used to assess response to therapy in clinical trials. However, despite its association with survival, WHO functional class is unsuitable as a primary outcome measure, due to its narrow range (ranking range from 1-4) and poor interrater agreement (46).

To address concerns about the validity of the 6MWT and the limited utility of WHO functional class as an outcome measure in $\mathrm{PAH}$, recent trials have used composite measures of morbidity and mortality or time to clinical worsening as primary outcome measures (47). However, no parallel-group randomized clinical trial has examined a patient-important outcome as a primary measure.

In a recent large retrospective study, McCabe and colleagues demonstrate the utility of the CAMPHOR for the prediction of clinical events in a cohort of patients with either IPAH or CTEPH (24). Baseline CAMPHOR scores were strongly predictive of clinical deterioration, defined as either need for escalation of therapy, hospital admission, lung transplantation, or death, overall and in both subgroups. However, these relationships did not persist in patients with IPAH when controlling for baseline 6MWD and WHO functional class, a finding the authors attribute to the close correlation between QOL and these parameters that is further confirmed in the current study. Importantly, the vast majority of the 61 observed events were either: (1) escalation of therapy ( $n=31$ [51\%]), or (2) hospital admission ( $\mathrm{n}=15$ [25\%]); deaths accounted for only $20 \%$ of the events $(n=12)$. Thus, the observed association between CAMPHOR and outcomes was largely driven by the need for augmentation of therapy and hospitalizations rather than deaths. Furthermore, unlike the current study, the relationship between baseline HRQOL and survival was not directly assessed.

Fernandes and colleagues recently reported on a Brazilian cohort of patients with various forms of PAH in whom SF-36 at baseline and after 16 weeks of $\mathrm{PAH}$ specific therapy was associated with longterm (3-yr) survival (26). The Brazilian cohort differs significantly from the current cohort, however, based on age (younger) and disease type ( $>80 \%$ IPAH or schistosomiasis-related PAH). Importantly, confounders of the relationship between HRQOL and outcomes, such as marital status, employment status, education level, and use of supplemental oxygen, were not reported (41). Furthermore, unlike the current study, multivariable models assessing the relationship between HRQOL and outcomes were not reported.

Although few data exist in $\mathrm{PAH}$, several studies in LHF have demonstrated significant associations between HRQOL and outcomes. Two randomized clinical trials have examined the utility of the SF-36 as a predictor of survival. In the Multicenter Automatic Defibrillator Implantation Trial (MADIT-II), a clinical trial of implantable cardiac defibrillator placement in more than

Table 4. Multivariable Cox proportional hazard models

\section{Parameter}

Unadjusted HR (95\% Cl; $\boldsymbol{P}$ Value)

\section{Adjusted* HR (95\% Cl; $P$ Value)}

\section{Adjusted $^{\dagger}$ HR} (95\% Cl; $P$ Value)

$\begin{array}{ll}\text { Social function } & 0.98(0.97-0.99 ; 0.02) \\ \text { Role physical } & 0.98(0.97-0.99 ; 0.05) \\ \text { Body pain } & 0.98(0.97-0.99 ; 0.01) \\ \text { General health } & 0.98(0.97-0.99 ; 0.01) \\ \text { Vitality } & 0.98(0.97-1.00 ; 0.10) \\ \text { Social function } & 0.98(0.97-0.99 ; 0.005) \\ \text { Role emotional } & 0.99(0.98-1.00 ; 0.08) \\ \text { Mental health } & 0.97(0.96-0.99 ; 0.01) \\ \text { Physical component summary } & 0.95(0.92-0.98 ; 0.009) \\ \text { Mental component summary } & 0.97(0.95-0.99 ; 0.006)\end{array}$

$0.98(0.96-0.99 ; 0.009)$

$0.99(0.98-0.99 ; 0.05)$

$0.98(0.97-0.99 ; 0.04)$

$0.98(0.97-0.99 ; 0.04)$

$0.99(0.97-1.01 ; 0.17)$

$0.98(0.97-0.99 ; 0.05)$

0.99 (0.98-1.00; 0.17)

0.97 (0.96-0.99; 0.01)

$0.96(0.93-1.00 ; 0.07)$

0.98 (0.96-0.99; 0.02)
$0.89(0.86-1.09 ; 0.54)$

$0.94(0.87-1.04 ; 0.56)$

$1.01(0.90-1.05 ; 0.38)$

$0.99(0.86-1.05 ; 0.27)$

$1.00(0.98-1.01 ; 0.29)$

$0.99(0.98-1.01 ; 0.06)$

$1.04(0.99-1.06 ; 0.26)$

$0.98(0.96-1.00 ; 0.10)$

$0.87(0.84-1.11 ; 0.35)$

$0.98(0.96-1.00 ; 0.08)$

Definition of abbreviations: $\mathrm{Cl}$ = confidence interval; CTD-PAH = connective tissue disease-associated pulmonary arterial hypertension; $\mathrm{HR}=$ hazard ratio; $\mathrm{IPAH}=$ idiopathic pulmonary arterial hypertension; $\mathrm{PAH}=$ pulmonary arterial hypertension.

Data presented as estimates of HR for transplant-free survival per 1-point increase in Medical Outcomes Survey Short Form-36 survey parameter.

*Adjusted for age at diagnosis of PAH, disease type (IPAH vs. CTD-PAH), and cardiac index.

${ }^{\dagger}$ Adjusted for age at diagnosis of PAH, disease type (IPAH vs. CTD-PAH), and World Health Organization functional class. 
1,000 postinfarction patients with depressed left ventricular function, lower PCS and MCS scores were associated with increased risk of death at 12 months in multivariable analyses controlling for age, sex, left ventricular ejection fraction, WHO functional class, heart rate, and renal function (20). Similarly, in a cohort from the Coordinating Study Evaluating Outcomes of Advising and Counseling in Heart Failure (COACH) study, a randomized clinical trial of disease management programs in 661 patients with LHF, SF-36 physical subscales (physical functioning, role physical, body pain, general health) predicted 3-year survival in unadjusted models, whereas physical function and general health subscales predicted survival in multivariable models (48). Observational studies of various cohorts of patients with LHF have also demonstrated associations between SF-36 and survival, both in short- and long-term follow up $(22,49,50)$.

Although the association between HRQOL and outcomes may be similar between these disease states, the magnitude of impact of clinically relevant changes in HRQOL on outcomes may differ (51). For instance, Hoekstra and colleagues report that a 10-unit decrease in physical function subscale (the minimal important difference [MID] for this parameter in LHF) was associated with an $8 \%$ increase risk of death at 3 years in LHF (HR, 1.08; 95\%

confidence interval [CI], 1.02-1.14 in multivariable models) (48). In our cohort, a clinically relevant change in physical functioning subscale, reported as 13 units by Gilbert and colleagues in a cohort of patients with $\mathrm{PAH}$, would be associated with a $24 \%$ increased risk of death (HR, 1.24; 95\% CI, 1.03-1.49) (52).

There are several limitations to the current study. First, as a single-center study, the findings may not be generalizable to other populations of patients with PAH. Second, although the relationships between SF-36 parameters and summary scores at baseline are consistently and significantly associated with outcomes, this study does not address the responsiveness of the SF-36 parameters to intervention or the predictive value of change in these parameters. In fact, most clinical trials of PAH therapies using the SF-36 to assess HRQOL have not demonstrated clinically relevant improvements in any parameter as assessed by the MID, defined as the smallest change in an outcome measure, perceived as beneficial, that would justify a change in a patient's medical management (23). However, exercise training in patients with various forms of $\mathrm{PH}$ was associated with a clinically relevant change in several domains of the SF-36 (53), similar to findings in LHF with exercise regimens using other HRQOL metrics (54).

Whether these changes in HRQOL were associated with improved outcomes in $\mathrm{PH}$ is unknown.

Third, the SF-36 is a generic measure of HRQOL and thus may not be as sensitive to change as disease-specific measures such as CAMPHOR. However, several studies in LHF have found similar or even stronger relationships between generic measures than disease-specific measures $(48,55)$. Furthermore, the utility of a disease-specific measure such as CAMPHOR in PAH is limited by the lack of a defined MID, length of the instrument, and lack of widespread availability due to its proprietary nature. Importantly, we did not assess for depression, which could impact the associations noted between HRQOL and outcomes, as has been previously shown in LHF (56).

Finally, other confounders for which we did not account could impact the observed relationships. As noted in the methods section, 6MWD was excluded from multivariable analyses due to collinearity. WHO functional class confounded the relationship between many of the domains of the SF-36 and outcomes. Although these findings suggest that these parameters may be measuring similar components of the spectrum of disease manifestations, collinearity and confounding were found predominantly in the physical domains of the SF-36. As shown in Table 4 , the change in point estimates for these domains most impacted by adjustment for WHO functional class (physical function, role physical, PCS) shows a larger magnitude of effect despite loss of statistical significance. Furthermore, the relationship between several mental domains of the SF-36 and outcomes was not substantially modified by the inclusion of WHO functional class. For example, when controlling for 6MWD, WHO functional class, and cardiac index, the magnitude of association between MCS and survival remained stable, whereas the strength of association was only slightly diminished $(\mathrm{HR}, 0.98$; 95\% CI, $0.96-1.00, P$ value $=$ 0.08 ). This highlights the utility of the SF-36 multidimensional assessment and its potential to provide additional prognostic information above and beyond the WHO functional class.

In conclusion, in this cohort of patients with PAH, HRQOL is significantly associated with transplant-free survival. These observations persist when adjusting for patient characteristics, disease type, and disease severity and thus highlight the importance of HRQOL in PAH. Future studies should focus on determining the relationship between changes in HRQOL and outcomes and identifying interventions to improve HRQOL.

Author disclosures are available with the tex of this article at www.atsjournals.org.

\section{References}

1 Simonneau G, Gatzoulis MA, Adatia I, Celermajer D, Denton C, Ghofrani A, Gomez Sanchez MA, Krishna Kumar R, Landzberg M, Machado RF, et al. Updated clinical classification of pulmonary hypertension. J Am Coll Cardiol 2013; 62:D34-D41.

2 Benza RL, Miller DP, Barst RJ, Badesch DB, Frost AE, McGoon MD. An evaluation of long-term survival from time of diagnosis in pulmonary arterial hypertension from the REVEAL Registry. Chest 2012;142: 448-456.

3 D'Alonzo GE, Barst RJ, Ayres SM, Bergofsky EH, Brundage BH, Detre KM, Fishman AP, Goldring RM, Groves BM, Kernis JT, et al. Survival in patients with primary pulmonary hypertension: results from a national prospective registry. Ann Intern Med 1991;115:343-349.

4 Benza RL, Miller DP, Gomberg-Maitland M, Frantz RP, Foreman AJ, Coffey CS, Frost A, Barst RJ, Badesch DB, Elliott CG, et al. Predicting survival in pulmonary arterial hypertension: insights from the Registry to Evaluate Early and Long-Term Pulmonary Arterial Hypertension Disease Management (REVEAL). Circulation 2010;122: 164-172.

5 Thenappan T, Glassner C, Gomberg-Maitland M. Validation of the pulmonary hypertension connection equation for survival prediction in pulmonary arterial hypertension. Chest 2012;141:642-650.

6 Humbert M, Sitbon O, Chaouat A, Bertocchi M, Habib G, Gressin V, Yaïci A, Weitzenblum E, Cordier JF, Chabot F, et al. Survival in 
patients with idiopathic, familial, and anorexigen-associated pulmonary arterial hypertension in the modern management era. Circulation 2010;122:156-163.

7 Fisher MR, Mathai SC, Champion HC, Girgis RE, Housten-Harris T, Hummers L, Krishnan JA, Wigley F, Hassoun PM. Clinical differences between idiopathic and scleroderma-related pulmonary hypertension. Arthritis Rheum 2006;54:3043-3050.

8 Shapiro S, Traiger GL, Turner M, McGoon MD, Wason P, Barst RJ. Sex differences in the diagnosis, treatment, and outcome of patients with pulmonary arterial hypertension enrolled in the registry to evaluate early and long-term pulmonary arterial hypertension disease management. Chest 2012;141:363-373.

9 Chung L, Liu J, Parsons L, Hassoun PM, McGoon M, Badesch DB, Miller DP, Nicolls MR, Zamanian RT. Characterization of connective tissue disease-associated pulmonary arterial hypertension from REVEAL: identifying systemic sclerosis as a unique phenotype. Chest 2010;138:1383-1394.

10 Forfia PR, Fisher MR, Mathai SC, Housten-Harris T, Hemnes AR, Borlaug BA, Chamera E, Corretti MC, Champion HC, Abraham TP, et al. Tricuspid annular displacement predicts survival in pulmonary hypertension. Am J Respir Crit Care Med 2006;174:1034-1041.

11 van de Veerdonk MC, Kind T, Marcus JT, Mauritz GJ, Heymans MW, Bogaard HJ, Boonstra A, Marques KM, Westerhof N, VonkNoordegraaf $A$. Progressive right ventricular dysfunction in patients with pulmonary arterial hypertension responding to therapy. J Am Coll Cardiol 2011;58:2511-2519.

12 van Wolferen SA, van de Veerdonk MC, Mauritz GJ, Jacobs W, Marcus JT, Marques KM, Bronzwaer JG, Heymans MW, Boonstra A, Postmus PE, et al. Clinically significant change in stroke volume in pulmonary hypertension. Chest 2011;139:1003-1009.

13 van Wolferen SA, Marcus JT, Boonstra A, Marques KM, Bronzwaer JG, Spreeuwenberg MD, Postmus PE, Vonk-Noordegraaf A. Prognostic value of right ventricular mass, volume, and function in idiopathic pulmonary arterial hypertension. Eur Heart $J$ 2007;28:1250-1257.

14 Doward LC, McKenna SP. Defining patient-reported outcomes. Value Health 2004;7:S4-S8.

15 Schipper H, Clinch J, Powell V. Definitions and conceptual issues. In: Spiker B, editor. Quality of life assessments in clinical trials. New York: Raven Press; 1990. pp. 11-24.

16 Ware JE Jr, Sherbourne CD. The MOS 36-item short-form health survey (SF-36): I. Conceptual framework and item selection. Med Care 1992;30:473-483.

17 Domingo-Salvany A, Lamarca R, Ferrer M, Garcia-Aymerich J, Alonso J, Félez M, Khalaf A, Marrades RM, Monsó E, Serra-Batlles J, et al. Health-related quality of life and mortality in male patients with chronic obstructive pulmonary disease. Am J Respir Crit Care Med 2002;166:680-685.

18 Esteban C, Quintana JM, Aburto M, Moraza J, Egurrola M, España PP, Pérez-Izquierdo J, Capelastegui A. Predictors of mortality in patients with stable COPD. J Gen Intern Med 2008;23:1829-1834.

19 Fan VS, Curtis JR, Tu SP, McDonell MB, Finn SD; Ambulatory Care Quality Improvement Project Investigators. Using quality of life to predict hospitalization and mortality in patients with obstructive lung diseases. Chest 2002;122:429-436.

20 Piotrowicz K, Noyes K, Lyness JM, McNitt S, Andrews ML, Dick A, Hall WJ, Moss AJ, Zareba W. Physical functioning and mental well-being in association with health outcome in patients enrolled in the Multicenter Automatic Defibrillator Implantation Trial II. Eur Heart J 2007;28:601-607.

21 Mommersteeg PM, Denollet J, Spertus JA, Pedersen SS. Health status as a risk factor in cardiovascular disease: a systematic review of current evidence. Am Heart J 2009;157:208-218.

22 Alla $F$, Briançon $S$, Guillemin F, Juillière $Y$, Mertès PM, Villemot JP, Zannad F; EPICAL Investigators. Self-rating of quality of life provides additional prognostic information in heart failure: insights into the EPICAL study. Eur J Heart Fail 2002;4:337-343.

23 Rival G, Lacasse Y, Martin S, Bonnet S, Provencher S. Effect of pulmonary arterial hypertension-specific therapies on health-related quality of life: a systematic review. Chest 2014;146:686-708.

24 McCabe C, Bennett M, Doughty N, MacKenzie Ross R, Sharples L, Pepke-Zaba J. Patient-reported outcomes assessed by the
CAMPHOR questionnaire predict clinical deterioration in idiopathic pulmonary arterial hypertension and chronic thromboembolic pulmonary hypertension. Chest 2013;144:522-530.

25 Cenedese E, Speich R, Dorschner L, Ulrich S, Maggiorini M, Jenni R, Fischler M. Measurement of quality of life in pulmonary hypertension and its significance. Eur Respir J 2006;28:808-815.

26 Fernandes CJ, Martins BC, Jardim CV, Ciconelli RM, Morinaga LK, Breda AP, Hoette S, Souza R. Quality of life as a prognostic marker in pulmonary arterial hypertension. Health Qual Life Outcomes 2014;12: 130.

27 Chen H, De Marco T, Kobashigawa EA, Katz PP, Chang VW, Blanc PD. Comparison of cardiac and pulmonary-specific quality-of-life measures in pulmonary arterial hypertension. Eur Respir J 2011;38: 608-616.

28 Suber T, Shao K, Bueso M, Hummers L, Hassoun PM, Mathai SC. Impact of health-related quality of life on outcomes in pulmonary arterial hypertension differs by disease type [abstract]. Am J Respir Crit Care Med 2013;187:A5376.

29 McHorney CA, Ware JE Jr, Lu JF, Sherbourne CD. The MOS 36-item Short-Form Health Survey (SF-36): III. Tests of data quality, scaling assumptions, and reliability across diverse patient groups. Med Care 1994;32:40-66.

30 Pepke-Zaba J, Beardsworth A, Chan M, Angalakuditi M. Tadalafil therapy and health-related quality of life in pulmonary arterial hypertension. Curr Med Res Opin 2009;25:2479-2485.

31 Pepke-Zaba J, Gilbert C, Collings L, Brown MC. Sildenafil improves health-related quality of life in patients with pulmonary arterial hypertension. Chest 2008;133:183-189.

32 Hoeper MM, Bogaard HJ, Condliffe R, Frantz R, Khanna D, Kurzyna M, Langleben D, Manes A, Satoh T, Torres F, et al. Definitions and diagnosis of pulmonary hypertension. J Am Coll Cardiol 2013;62: D42-D50.

33 Seeger W, Adir Y, Barberà JA, Champion H, Coghlan JG, Cottin V, De Marco T, Galiè N, Ghio S, Gibbs S, et al. Pulmonary hypertension in chronic lung diseases. J Am Coll Cardiol 2013;62:D109-D116.

34 Aletaha D, Neogi T, Silman AJ, Funovits J, Felson DT, Bingham CO III, Birnbaum NS, Burmester GR, Bykerk VP, Cohen MD, et al. 2010 Rheumatoid arthritis classification criteria: an American College of Rheumatology/European League Against Rheumatism collaborative initiative. Arthritis Rheum 2010;62:2569-2581.

35 Shiboski SC, Shiboski CH, Criswell L, Baer A, Challacombe S, Lanfranchi $\mathrm{H}$, Schiødt $\mathrm{M}$, Umehara $\mathrm{H}$, Vivino $\mathrm{F}$, Zhao $\mathrm{Y}$, et al.; Sjögren's International Collaborative Clinical Alliance (SICCA) Research Groups. American College of Rheumatology classification criteria for Sjögren's syndrome: a data-driven, expert consensus approach in the Sjögren's International Collaborative Clinical Alliance cohort. Arthritis Care Res (Hoboken) 2012;64:475-487.

36 Hochberg MC. Updating the American College of Rheumatology revised criteria for the classification of systemic lupus erythematosus. Arthritis Rheum 1997;40:1725.

37 van den Hoogen F, Khanna D, Fransen J, Johnson SR, Baron M, Tyndall A, Matucci-Cerinic M, Naden RP, Medsger TA Jr, Carreira $\mathrm{PE}$, et al. 2013 classification criteria for systemic sclerosis: an American College of Rheumatology/European League against Rheumatism collaborative initiative. Arthritis Rheum 2013;65: $2737-2747$.

38 Cox DR. Regression models and life-tables. J R Stat Soc Series B Stat Methodol 1972;34:187-220.

39 Schoenfeld DA. Sample-size formula for the proportional-hazards regression model. Biometrics 1983;39:499-503.

40 Hess KR. Graphical methods for assessing violations of the proportional hazards assumption in Cox regression. Stat Med 1995;14:1707-1723.

41 Taichman DB, Shin J, Hud L, Archer-Chicko C, Kaplan S, Sager JS, Gallop R, Christie J, Hansen-Flaschen J, Palevsky H. Health-related quality of life in patients with pulmonary arterial hypertension. Respir Res 2005;6:92.

42 Roman A, Barbera JA, Castillo MJ, Muñoz R, Escribano P. Healthrelated quality of life in a national cohort of patients with pulmonary arterial hypertension or chronic thromboembolic pulmonary hypertension. Arch Bronconeumol 2013;49:181-188. 
43 McLaughlin VV, Gaine SP, Howard LS, Leuchte HH, Mathier MA, Mehta S, Palazzini M, Park MH, Tapson VF, Sitbon O. Treatment goals of pulmonary hypertension. J Am Coll Cardiol 2013;62:D73-D81.

44 Gabler NB, French B, Strom BL, Palevsky HI, Taichman DB, Kawut SM, Halpern SD. Validation of 6-minute walk distance as a surrogate end point in pulmonary arterial hypertension trials. Circulation 2012;126: 349-356.

45 Mathai SC. Solvitur ambulando...or maybe not? Chest 2013;143: 285-287.

46 Taichman DB, McGoon MD, Harhay MO, Archer-Chicko C, Sager JS, Murugappan M, Chakinali MM, Palevsky HI, Gallop R. Wide variation in clinicians' assessment of New York Heart Association/World Health Organization functional class in patients with pulmonary arterial hypertension. Mayo Clin Proc 2009;84:586-592.

47 Pulido T, Adzerikho I, Channick RN, Delcroix M, Galiè N, Ghofrani HA, Jansa P, Jing ZC, Le Brun FO, Mehta S, et al.; SERAPHIN Investigators. Macitentan and morbidity and mortality in pulmonary arterial hypertension. N Engl J Med 2013;369:809-818.

48 Hoekstra T, Jaarsma T, van Veldhuisen DJ, Hillege HL, Sanderman R, Lesman-Leegte I. Quality of life and survival in patients with heart failure. Eur J Heart Fail 2013;15:94-102.

49 Zuluaga MC, Guallar-Castillón P, López-García E, Banegas JR, Conde-Herrera M, Olcoz-Chiva M, Rodríguez-Pascual C, RodriguezArtalejo F. Generic and disease-specific quality of life as a predictor of long-term mortality in heart failure. Eur J Heart Fail 2010;12: 1372-1378.

50 Chamberlain AM, McNallan SM, Dunlay SM, Spertus JA, Redfield MM, Moser DK, Kane RL, Weston SA, Roger VL. Physical health status measures predict all-cause mortality in patients with heart failure. Circ Heart Fail 2013;6:669-675.

51 Wyrwich KW, Tierney WM, Babu AN, Kroenke K, Wolinsky FD. A comparison of clinically important differences in health-related quality of life for patients with chronic lung disease, asthma, or heart disease. Health Serv Res 2005;40:577-591.

52 Gilbert C, Brown MC, Cappelleri JC, Carlsson M, McKenna SP. Estimating a minimally important difference in pulmonary arterial hypertension following treatment with sildenafil. Chest 2009;135: 137-142.

53 Mereles D, Ehlken N, Kreuscher S, Ghofrani S, Hoeper MM, Halank M, Meyer FJ, Karger G, Buss J, Juenger J, et al. Exercise and respiratory training improve exercise capacity and quality of life in patients with severe chronic pulmonary hypertension. Circulation 2006;114: 1482-1489.

54 Flynn KE, Piña IL, Whellan DJ, Lin L, Blumenthal JA, Ellis SJ, Fine LJ, Howlett JG, Keteyian SJ, Kitzman DW, et al.; HF-ACTION Investigators. Effects of exercise training on health status in patients with chronic heart failure: HF-ACTION randomized controlled trial. JAMA 2009;301:1451-1459.

55 Lupón J, Gastelurrutia P, de Antonio M, González B, Cano L, Cabanes R, Urrutia A, Díez C, Coll R, Altimir S, et al. Quality of life monitoring in ambulatory heart failure patients: temporal changes and prognostic value. Eur J Heart Fail 2013;15:103-109.

56 Murberg TA, Bru E, Aarsland T, Svebak S. Functional status and depression among men and women with congestive heart failure. Int J Psychiatry Med 1998;28:273-291. 